\title{
Da vigilância para prevenção de acidentes de trabalho: contribuição da ergonomia da atividade
}

\author{
From surveillance to work-related accident prevention: \\ the contribution of the ergonomics of the activity
}

Rodolfo Andrade de Gouveia Vilela ${ }^{1}$

Ildeberto Muniz de Almeida ${ }^{2}$

Renata Wey Berti Mendes ${ }^{3}$

${ }^{1}$ Faculdade Saúde Pública, Universidade de São Paulo (USP). Dr. Arnaldo 715, Cerqueira Cesar. 01246-904 São Paulo SP. ravilela@usp.br ${ }^{2}$ Departamento de Saúde Pública, Faculdade de Medicina de Botucatu, Universidade Estadual Paulista Júlio de Mesquita Filho.

${ }^{3}$ Centro de Referência em Saúde do Trabalhador (Cerest), Secretaria Municipal de Saúde de Piracicaba.
Abstract Work-related accidents are complex phenomena determined by the work organization process, the dimensions of which are usually invisible to surveillance agents. The scope of this paper was a case study based on documentary evidence to analyze and compare the success of an intervention conducted at a meat processing and packaging factory, by focusing on checking health and safety norms in 1997, and incorporating ergonomic concepts in 2008. In 1997, surveillance actions focused primarily on visible risk factors. Despite fulfilling sanitation requirements, the company still had an annual accident rate of $26 \%$ in 2008, which motivated the search for a new approach. In 2008, it was seen that accidents were caused by a vicious cycle involving intense work, technical inadequacy, absenteeism and high turnover (84\%) that led the company to recruit inexperienced workers. This scenario was aggravated by authoritarian management practices. The ergonomics of the activity contributed to the understanding of organizational causes -thus superseding the normative aspects of traditional surveillance - which revealed the importance of ensuring that surveillance actions for prevention are more effective.

Key words Work-related accident, Worker's health surveillance, Ergonomic activity, Meat processing and packaging company
Resumo Os acidentes são fenômenos complexos, cuja determinação situa-se na organização do trabalho, dimensão invisivel aos agentes de vigilância. O objetivo deste artigo é analisar e comparar o alcance das intervençães realizadas em uma empresa frigorifica, em 1997, baseada na checagem de normas de saúde e segurança, e em 2008, quando se incorpora a ergonomia da atividade. Foi realizado estudo de caso com análise documental referente à intervenção de 1997 e análise ergonômica do trabalho adotada em 2008. Em 1997 as ações de vigilância incidiram principalmente sobre os fatores de risco visíveis. Mesmo cumprindo as exigências, a empresa continuava, em 2008, com proporção de incidência anual de 26\% de acidentes, $o$ que motivou a busca da nova abordagem. Verificou-se, em 2008, que a gênese dos acidentes era provocada por um circulo vicioso: trabalho intenso; inadequação de meios técnicos; absenteísmo e rotatividade ( $84 \%$ ao ano) com recrutamento de inexperientes. Esse quadro é agravado por práticas autoritárias. A ergonomia da atividade contribuiu para compreender as causas organizacionais ultrapassando os aspectos normativos da vigilância tradicional, o que indica sua importância para tornar mais efetivas as ações de vigilância para a prevenção.

Palavras-chave Acidente de trabalho, Vigilância em saúde do trabalhador, Ergonomia da atividade, Frigorífico de abate de bovinos e suinos 


\section{Introdução}

Os acidentes do trabalho constituem o principal agravo à saúde dos trabalhadores, com elevados custos sociais e econômicos que podem chegar a $10 \%$ do PIB (Produto Interno Bruto) ${ }^{1}$.

Esses acidentes são influenciados por aspectos da situação imediata de trabalho como o maquinário, a tarefa, o meio técnico ou material, mas também pelas relações de trabalho ${ }^{2}$, cuja determinação situa-se na sua organização ${ }^{3,4}$.

A despeito das críticas às abordagens tradicionais, ainda prevalece uma visão reducionista e tendenciosa de que esses eventos possuem uma ou poucas causas decorrentes de falhas dos operadores (erro humano, ato inseguro, comportamento fora do padrão, etc.) associadas ao descumprimento de normas e padrões de segurança ou a falhas técnicas e materiais ${ }^{5,6}$.

Esse enfoque herdado de disciplinas clássicas como a Higiene e Saúde Ocupacional é insuficiente para explicar o processo causal dos acidentes e da nocividade, o que limita as ações de vigilância e prevenção, ao deixar intocados os determinantes desses eventos ${ }^{7-9}$.

A vigilância em saúde do trabalhador no SUS (Sistema Único de Saúde) tem sido abordada em perspectiva sociotécnica, na qual a prevenção pode surgir de ações estratégicas articuladas interinstitucionalmente, de modo a analisar e a intervir nos fatores determinantes e condicionantes dos problemas de saúde relacionados aos processos de trabalho ${ }^{10}$.

A despeito de avanços práticos e teóricos, um dos grandes desafios dos agentes públicos é identificar os determinantes dos acidentes e da nocividade e, a partir desse diagnóstico, desencadear ações de prevenção.

Para enfrentar a elevada acidentalidade no Município de Piracicaba, o PST (Programa de Saúde do Trabalhador) promove ações de intervenção e vigilância em articulação interinstitucional com participação de sindicatos de trabalhadores e do MTE (Ministério do Trabalho e Emprego) desde o ano de $1997^{11}$. Essa articulação vem sendo ampliada e, em 2003, o PST já habilitado como Cerest Piracicaba (Centro de Referência em Saúde do Trabalhador), incluiu a academia em projeto conjunto de pesquisa em políticas públicas, viabilizando o Sivat (Sistema de Vigilância de Acidentes de Trabalho), que consiste na notificação dos eventos nas unidades de urgência, processamento dos dados e intervenção nos casos graves e fatais, ou nas empresas com maior proporção de incidência ${ }^{12}$.
De 2006 a 2009, foi desenvolvido o segundo projeto de pesquisa com apoio da Fapesp (Fundação de Amparo à Pesquisa do Estado de São Paulo), tendo como objeto aprimorar o Sivat. Para tanto foi incorporada a contribuição da ergonomia da atividade ${ }^{13,14}$, resultando, entre outros produtos, na elaboração do MAPA (Modelo de Análise e Prevenção de Acidentes) ${ }^{15}$, desenvolvido para melhor compreender por que empresas com elevadas proporções de incidência de AT, mesmo sendo objeto de ações sistemáticas de vigilância, não abaixavam esses índices.

Entre essas empresas, destacava-se um frigorífico de abate de bovinos e suínos, objeto de intervenção analisada no presente artigo.

Em nível nacional, esse ramo vem apresentando aumento do risco de acidentes medido pela incidência anual que era de 41,2 por mil ocupados em 2002 e cresceu para 46,3 por mil em 2005, sendo a faca o principal objeto causador, envolvida em $43,3 \%$ dos $\operatorname{casos}^{16}$.

O objetivo do presente artigo é analisar e comparar o alcance das intervenções de vigilância de acidentes de trabalho realizadas na empresa frigorífica, em dois momentos: 1997, quando se praticou a vigilância centrada na checagem de itens de legislação em saúde e segurança; e, em 2008, quando se incorporou o olhar da ergonomia da atividade.

As ações de vigilância em Saúde do Trabalhador preconizam a importância da investigação do processo e a organização do trabalho em sua relação com a saúde. No entanto essa diretriz não se traduz em uma metodologia dominada pelos profissionais desses serviços. Uma referência comum nas áreas do trabalho e da saúde são as NRs (Normas Regulamentadoras) definidas pela Portaria 3214/78 ${ }^{17}$ do Ministério do Trabalho e Emprego e usadas como base para regular as condições de trabalho e prevenção de riscos (segurança em máquinas, trabalho em altura, eletricidade, proteções individuais e coletivas, riscos ambientais, ergonomia, etc.). No entanto, para aprofundar a busca de determinantes, especialmente os organizacionais, é preciso se voltar à NR 17, raramente utilizada, que prevê a realização da Análise Ergonômica do Trabalho, metodologia que requer estudo minucioso do processo e da organização do trabalho.

Nossa hipótese sugere que ter desconsiderado no passado os aspectos da organização do trabalho e práticas gerenciais consideradas propícias aos acidentes pode ter contribuído para a persistência da elevada acidentalidade na organização estudada. 
O estudo foi aprovado pelo Comitê de Ética em Pesquisa da Unimep (Universidade Metodista de Piracicaba).

\section{Metodologia e conceitos empregados}

A análise de documentos do PST possibilitou resgatar o histórico da intervenção na empresa. A intervenção de 1997 foi realizada em articulação do PST com o auditor fiscal do MTE e representantes do Sindicato dos Trabalhadores. Naquele ano, realizou-se observação do processo produtivo e verificação de perigos e riscos. Condições de trabalho foram fotografadas e classificadas de acordo com itens das NRs, combinadas com itens do Código Sanitário Federal (Lei 6.437/ $1977)^{18}$. Porém as inspeções foram acompanhadas por representantes da empresa, dificultando a livre manifestação dos trabalhadores.

Em seguida, foram lavrados autos de infração sanitária, concedendo-se prazos para o atendimento das exigências. Situações de risco grave e iminente geraram interdições para correção imediata. Condições menos críticas foram objeto de mesas redondas, definindo-se cronogramas para cumprimento dos prazos. Os compromissos e os prazos não atendidos geraram penalidades administrativas pelo PST e encaminhamento ao MPT (Ministério Público do Trabalho) da 15a Região.

Em 2008, o Cerest realizou análise em profundidade na empresa com base na ergonomia da atividade ${ }^{13,14}$.

A abordagem foi escolhida por possibilitar compreender o trabalho humano em situação real. O conhecimento da relação trabalho-saúde é obtido na interação do pesquisador com o operador, numa abordagem de baixo para cima. Ela tem como pressuposto a diferenciação entre o trabalho prescrito - designado de tarefa como sendo aquilo que é pedido - e o trabalho real ou atividade - o que é feito pelo operador para dar conta do que lhe é pedido. A atividade de trabalho é uma estratégia de adaptação à situação real de trabalho, objeto de prescrição. A distância entre o trabalho prescrito e o real é a manifestação concreta da contradição sempre presente no ato de trabalho: entre o que é pedido e o que a coisa pede ${ }^{13}$.

Esse método mostra que o operador não é neutro diante dos constrangimentos surgidos na sua relação com o trabalho. Ou seja, ele desenvolve estratégias, modos operatórios e regulações para se adaptar e atender as exigências de produção, levando em conta o seu estado interno, o menor custo energético e cognitivo, a sua segurança e a do sistema ${ }^{7}$. Entende-se por operador o agente direto da produção. No caso específico do frigorífico, trata-se de trabalhadores do setor de matança e os responsáveis pelo desmanche e preparo das peças dos animais.

Por estratégia, entende-se o plano desenvolvido pelo operador para conseguir seus objetivos. São os caminhos que devem orientar o operador no curso da ação, mantidas as condições idealizadas: materiais, interação com colegas, exigências temporais, etc. Por modo operatório, entende-se a maneira específica que cada operador adota na execução da tarefa, como o gestual utilizado, a velocidade empregada, a maneira de segurar e de cortar, ou seja, 'como ele faz para fazer ${ }^{14}$. Mudanças nas condições e aspectos associados às estratégias escolhidas exigem ajustes nos modos operatórios podendo afetar a segurança no trabalho.

A metodologia usada em 2008 consistiu na combinação dos seguintes instrumentos:

- Análise da demanda e seleção das situações a analisar;

- Análise Coletiva do Trabalho ${ }^{19}$ (ACT) com a participação de 53 trabalhadores do setor de matança. Ela consiste em reunião em grupo onde os trabalhadores explicam detalhadamente como é realizado seu trabalho, suas dificuldades, seu modo operatório e as estratégias e regulações que utilizam para dar conta da produção em situação real. Em pouco tempo, essa análise produz riqueza de informações objetivas e, simultaneamente, significa oportunidade para os trabalhadores expressarem sua subjetividade. A reunião de aproximadamente duas horas foi realizada no interior da empresa em horário de trabalho, tendo como requisito a não participação de chefias, encarregados e membros do SESMT (Serviço Especializado de Segurança e Medicina do Trabalho). Durante a ACT foram registradas verbalizações, posteriormente analisadas pela equipe;

- Observações do processo de trabalho, combinada com a análise de documentos e coleta de verbalizações dos operadores em situação real de trabalho, com a finalidade de compreender os modos operatórios e as estratégias usadas pelos mesmos;

- Checagem de instalações tendo como referência as normas de saúde e segurança vigentes;

- Seleção de acidentes mais frequentes do setor matança, considerado prioritário com base nos dados da empresa e do Sivat; e análise dos mesmos usando o MAPA. 
- O MAPA utiliza roteiro com as seguintes etapas: (a) Identificação das empresas e das vítimas; (b) Descrição do trabalho normal (sem acidentes); (c) Descrição do acidente propriamente dito que se subdivide em ( $\mathrm{cl}$ ) análise de mudanças e (c2) análise das barreiras de seu funcionamento na prevenção e proteção do operador; (d) medidas adotadas pela empresa depois do acidente; (e) análise de aspectos gerenciais e organizacionais; (f) análise da gestão de saúde e segurança do trabalho; (g) análise da gestão de produção, que pode se desdobrar na gestão de manutenção, de pessoal, de materiais, de projetos etc.; (h) síntese conclusiva sobre as origens do acidente; (i) recomendações de prevenção.

As recomendações extraídas do diagnóstico são apresentadas aos atores envolvidos (empresa, sindicato, Ministério do Trabalho) com a finalidade de desencadear processo de negociação em defesa de melhorias na situação existente. A pesquisa intervenção foi conduzida por quatro técnicos do Cerest, todos capacitados no uso do MAPA. Dois técnicos possuíam especialização em ergonomia.

O trabalho de campo demandou cerca de quatro meses em tempo parcial. O estudo foi supervisionado e seus resultados foram periodicamente apresentados e discutidos com a equipe de pesquisa.

A Figura 1 traz diagrama síntese da metodologia adotada em 2008.

\section{Resultados}

\section{A Primeira ação de vigilância (1997)}

Em 1997, o frigorífico apresentava proporção de incidência anual de AT de 22,05\%, a terceira pior posição entre as empresas do município.

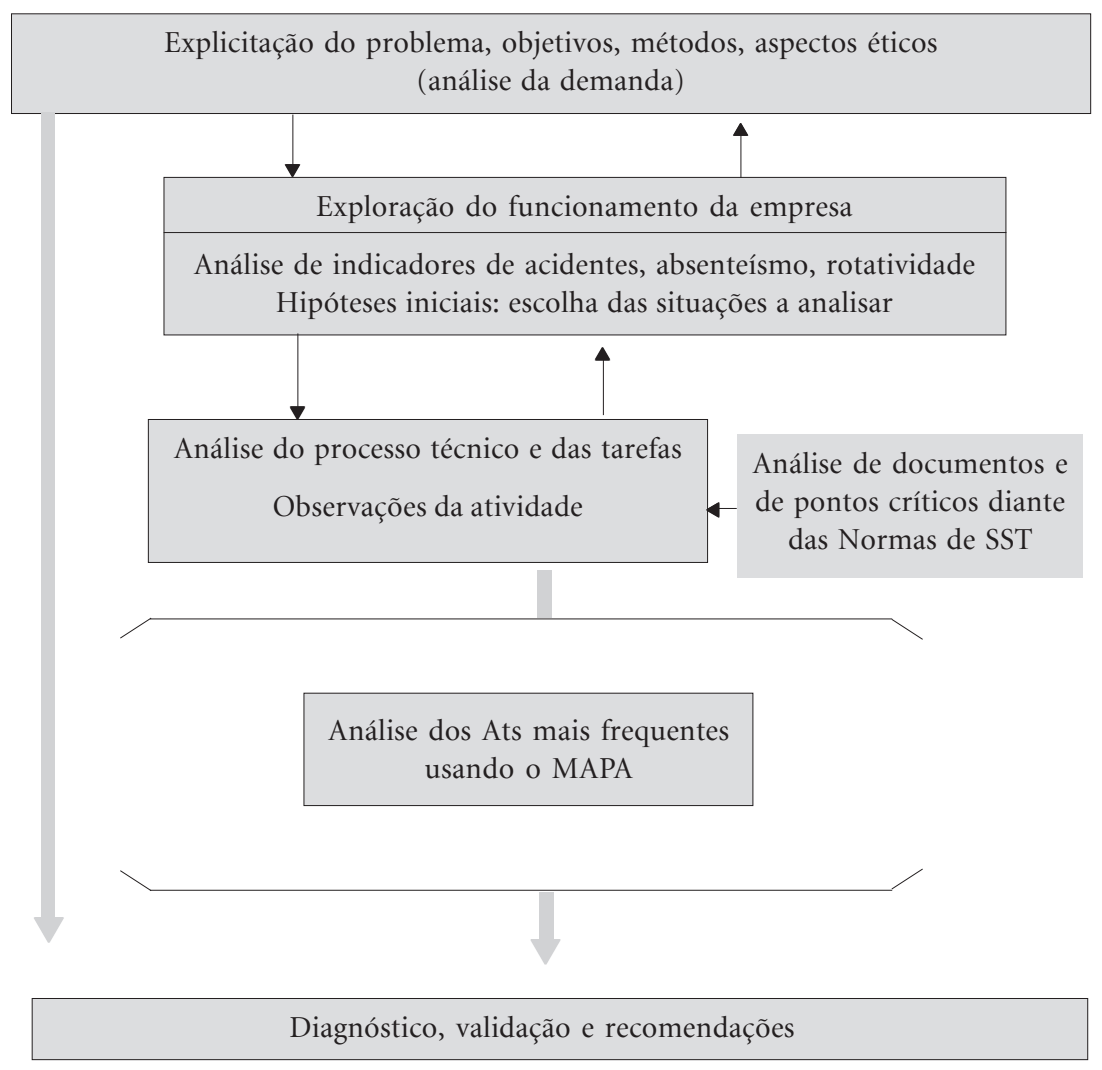

7

Reunião com sindicato e com a direção da empresa I

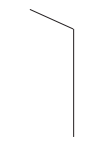

Interação com os operadores *

Oficinas \& entrevistas *

Observação em situação

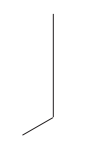

Figura 1. Diagrama síntese do método usado no estudo. 
As causas imediatas dos AT eram manuseio de facas, realização de força e movimentação de peso, conforme banco de dados das CAT (Comunicações de Acidentes de Trabalho), processadas pelo PST de Piracicaba. A proporção de incidência anual de AT foi calculada com base nos acidentes típicos registrados pelas CAT, emitidas pela empresa no período de 1997 a 2008, e adotada como o indicador de risco. Esse indicador é calculado como segue: (número de AT no ano / número médio de funcionários no ano) x100.

O frigorífico estudado é uma empresa de médio porte de abate de bovinos e suínos. Os animais são transportados dos currais para o setor de matança e, após o abate, são pendurados por meio de correntes e ganchos em transportador aéreo mecanizado, denominado nória, que conduz os animais durante todo o processo de desmanche. A nória assegura o deslocamento contínuo das peças dos animais até chegar à câmara fria ("tendal") e à área de expedição das peças de carne.

Na ocasião do estudo, os bovinos eram mortos com pistola automática, enquanto os suínos eram mortos à faca. A nória possuía velocidade constante de 10 metros por minuto. Os dois fluxos de desmanche de bovinos e suínos, com exceção do abate, ocorriam nos mesmos postos de trabalho, sendo que o abate dos bovinos (de 300 a 600 bois ao dia) era realizado pela manhã; e o dos suínos (300 a 500 ao dia), realizado pelos mesmos operadores, no período da tarde.

Em 1997, foi realizada a primeira intervenção conforme descrito na metodologia. Após a correção de situações de risco grave e iminente, e decorridos os prazos concedidos aos demais itens, foi realizada, em 1999, nova inspeção para checagem completa do cumprimento das exigências. $\mathrm{O}$ não atendimento de alguns itens resultou na aplicação de penalidade de multa pelo PST. A empresa foi monitorada e autuada até 2007, quando ainda continuava com elevada taxa de incidência de acidentes. No período estudado (1997 a 2008), a média de acidentes típicos por ano foi de 84, para média anual de 320 funcionários.

O Gráfico 1 mostra a evolução da proporção anual de incidência de AT na empresa.

A linha de tendência mostra leve crescimento de risco de AT, a despeito das ações de vigilância no período de 1997 a 2008. A série histórica evidencia a importância de análise crítica dessas intervenções, de modo a entender suas limitações com vistas a seu aprimoramento.

Cabe ressaltar que não ocorreram no período alterações significativas no processo de trabalho, seja nos aspectos técnicos materiais seja na

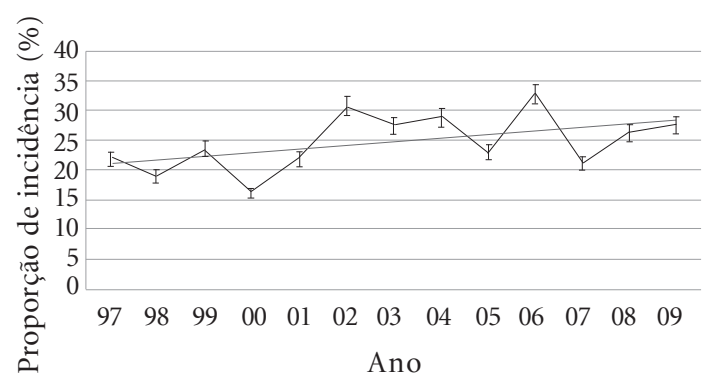

Gráfico 1. Proporção de incidência de ATs (\%) na empresa no período de 1997 a 2008.

Base de dados: CATs emitidas pela empresa; média da proporção de incidência no período: $24,73(\%)$.

forma de gestão da produção e de segurança, capazes de explicar a evolução dos riscos.

No Quadro 1, as duas colunas do lado esquerdo sintetizam o resultado da primeira ação de vigilância de 1997. Na primeira, constam as exigências do PST, conforme registros em autos de infração e termos de interdição. A segunda coluna mostra a situação de cumprimento das referidas exigências, conforme inspeção realizada no ano de 1999.

A intervenção realizada no ano de 1997 incidiu sobre 11 itens referentes às condições técnicas e materiais, aqueles visíveis aos agentes de inspeção; e quatro referentes aos aspectos de gestão em saúde e segurança do trabalho, os previstos na legislação vigente. Observa-se que a dimensão organizacional e de gerenciamento da produção, como a questão da intensidade do trabalho, não aparece na primeira intervenção. No tocante ao gerenciamento dos riscos, verifica-se que as exigências recaem sobre aspectos previstos na legislação, como a implantação de PPRA (Programas de Prevenção de Riscos Ambientais) e de PCMSO (Programa de Controle Médico de Saúde Ocupacional), que se mostraram burocráticos, não resultando em melhorias das condições de trabalho e segurança.

\section{Para compreender os acidentes é preciso compreender o trabalho - A pesquisa / intervenção de 2008}

Em 2008, a empresa continuava entre as primeiras colocadas no ranking de acidentalidade do município com proporção de incidência de 26\% ao ano, ainda maior do que a de 1997 (23\% ao ano), segundo os dados das CAT. 
Quadro 1. Exigências formuladas na ação de vigilância de 1997, e situação encontrada conforme avaliado em 1999 ( $1^{\text {a }}$ e $2^{\text {a }}$ coluna) e de 2008 ( $3^{\text {a }}$ e $4^{\text {a }}$ coluna).

\begin{tabular}{|c|c|c|c|}
\hline Vigilância de 1997 & $\begin{array}{l}\text { Situação } \\
\text { em } 1999\end{array}$ & Pesquisa/intervenção de 2008 & $\begin{array}{l}\text { Situação } \\
\text { em } 2008\end{array}$ \\
\hline \multicolumn{2}{|l|}{ Gestão de Segurança } & \multicolumn{2}{|l|}{ Gestão de Segurança } \\
\hline Implantar PPRA. & Resolvido & $\begin{array}{l}\text { Manter um almoxarifado de EPI em cada setor } \\
\text { onde são usados, para facilitar e estimular o seu uso }\end{array}$ & $\begin{array}{l}\text { Negado pela } \\
\text { empresa }\end{array}$ \\
\hline Implantar PCMSO. & Resolvido & \multirow[t]{3}{*}{$\begin{array}{l}\text { Alterar sistema de controle de EPI eliminando } \\
\text { práticas ilegais de cobrança (desconto em salário) } \\
\text { e punição aos trabalhadores quando ocorre } \\
\text { desgaste ou outro motivo. }\end{array}$} & \multirow[t]{3}{*}{$\left({ }^{*}\right)$} \\
\hline $\begin{array}{l}\text { Implantar manual de segurança com } \\
\text { instruções de trabalho para atividades } \\
\text { de produção e manutenção. }\end{array}$ & Resolvido & & \\
\hline $\begin{array}{l}\text { Implantar Serviço Especializado em } \\
\text { Segurança e Medicina do Trabalho } \\
\text { SESMT. }\end{array}$ & Resolvido & & \\
\hline \multicolumn{2}{|l|}{ Materiais e Equipamentos } & \multicolumn{2}{|l|}{ Materiais e Equipamentos } \\
\hline $\begin{array}{l}\text { Implantar guarda-corpos em todas } \\
\text { plataformas, mezaninos e escadas. }\end{array}$ & Resolvido & $\begin{array}{l}\text { Implantar pistola pneumática para injetar ar } \\
\text { comprimido no crânio do boi e promover a } \\
\text { morte imediata do animal. }\end{array}$ & $\begin{array}{l}\text { Aceito/ } \\
\text { Resolvido }\end{array}$ \\
\hline \multirow[t]{3}{*}{$\begin{array}{l}\text { Implantar barreiras de proteção em } \\
\text { todas as máquinas especialmente nos } \\
\text { mecanismos de transmissão de força } \\
\text { (polias, correias, engrenagens). }\end{array}$} & \multirow[t]{3}{*}{ Resolvido } & $\begin{array}{l}\text { Instalar sistema de abate de suínos a base de choque } \\
\text { elétrico de modo a eliminar os postos mais penosos } \\
\text { e perigosos: içar o porco pelas patas; matar o porco } \\
\text { com punhal e puxar o porco com o gancho. }\end{array}$ & $\begin{array}{l}\text { Aceito - } \\
\text { cronograma } \\
\text { de mudança }\end{array}$ \\
\hline & & $\begin{array}{l}\text { Equacionar situação dos EPIs por meio de busca de } \\
\text { luvas à prova de rompimento e desgaste dos elos. }\end{array}$ & $\begin{array}{c}\text { Pendente a } \\
\text { depender de } \\
\text { disponibilidade } \\
\text { no mercado. }\end{array}$ \\
\hline & & \multicolumn{2}{|l|}{ Org. trabalho /Gestão de Produção } \\
\hline Instalar bebedouros em toda fábrica & Resolvido & $\begin{array}{l}\text { Aumentar o número de funcionários durante } \\
\text { período de elevada demanda (setembro a janeiro) a } \\
\text { fim de diminuir o risco de acidentes e outras lesões. }\end{array}$ & $\begin{array}{l}\text { Aceito } \\
\text { Resolvido }\end{array}$ \\
\hline $\begin{array}{l}\text { Instalar mecanismos de parada de } \\
\text { emergência em todas máquinas e } \\
\text { equipamentos. }\end{array}$ & Resolvido & $\begin{array}{l}\text { Aumentar o número de funcionários nos setores: } \\
\text { câmara fria, sala de desossa, sala de mocotó, e } \\
\text { sala de miúdo para que os trabalhadores da } \\
\text { matança não sejam mais deslocados no final da } \\
\text { jornada para estes setores. }\end{array}$ & $\begin{array}{l}\text { Negado pela } \\
\text { empresa }\end{array}$ \\
\hline $\begin{array}{l}\text { Providenciar melhorias nos pisos da } \\
\text { fábrica para evitar queda de mesmo } \\
\text { nível. }\end{array}$ & $\begin{array}{l}\text { Parcialmente } \\
\text { resolvido }\end{array}$ & \multirow[t]{3}{*}{$\begin{array}{l}\text { Suprimir práticas autoritárias de Gestão de } \\
\text { Pessoas (suspensão ou "gancho"). }\end{array}$} & \multirow[t]{3}{*}{$\begin{array}{l}\text { Negado pela } \\
\text { empresa }\end{array}$} \\
\hline $\begin{array}{l}\text { Providenciar proteção contra queda } \\
\text { dos ganchos sobre os trabalhadores } \\
\text { (os ganchos caiam da nória). }\end{array}$ & $\begin{array}{l}\text { Resolvido no } \\
\text { setor } \\
\text { matança }\end{array}$ & & \\
\hline $\begin{array}{l}\text { Providenciar fornecimento gratuito e } \\
\text { assegurar uso de EPIs especialmente } \\
\text { luva de aço para o setor de matança. }\end{array}$ & $\begin{array}{l}\text { Resolvido } \\
\text { quanto ao } \\
\text { fornecimento. } \\
\text { Uso regular } \\
\text { continua } \\
\text { pendente. }\end{array}$ & & \\
\hline
\end{tabular}

${ }^{*}$ Por se tratar de prática ilegal o item foi retirado pelo Cerest da mesa de negociação e foi remetido para o MPT para ações cabíveis. 
A análise dos dados da empresa apontou o setor de matança como prioritário com proporção de incidência estimada em 49\% em 2008, tendo como causa imediata principal o manuseio de facas. As mãos e os membros inferiores foram as principais partes do corpo atingidas.

Por ser linha de desmanche típica, que associa fragmentação da tarefa com transporte mecanizado pela nória, o trabalho de um operador depende da sua posição como explicado na verbalização do operador:

- Se acontecer alguma coisa atrapalha a linha inteira; um depende do outro [...] se um atrasar, o outro tem que correr e fazer o serviço.

Fator relevante para a atividade é a velocidade da nória. Ela é mantida a $10 \mathrm{~m} / \mathrm{min}$ ao longo de todo o processo, para todos os postos de trabalho, independentemente das tarefas dos operadores. No final da linha, onde se faz a inspeção, a exigência é mais cognitiva e de observação. Aí, a velocidade da nória parece adequada. Porém, no início da linha, em que a atividade consiste em cortar, sangrar e cortar de novo, a velocidade se mostra excessiva. Dada a falta de margem de manobra, a alternativa que resta aos operadores para cumprir as metas impostas é a aceleração de modos operatórios, aumentando as chances de cansaço e de erros com prejuízos potenciais à qualidade e à segurança do trabalho.

A divisão das tarefas se dá de acordo com competências práticas dos operadores. Para a função de magarefe, que é a de separar o couro da carne do animal, há exigência de experiência e destreza para cortes precisos, pois não se pode cortar nem o couro nem a carne. Para todas as outras funções no setor de matança, não é exigida experiência. A formação consiste em aprendizado prático, obtido com os colegas, sem período de adaptação, tendo o operador que dar conta da tarefa em ritmo acelerado, acompanhando a nória.

- Não tem treinamento [...] dois dias e a gente já está com a faca na mão [...] eles dão a faca e manda se virar... O acidente acontece mais com quem não tem prática.

Embora a referência à falta de treinamentos assuma contornos mais precisos ao ser associada à habilidade manual requerida na atividade, sua utilização embute a chance de incompreensões sobre aspectos da complexidade do trabalho real no frigorífico e da formação necessária para a sua realização. Dar a faca e mandar se virar após dois dias acompanhando o trabalho de experientes não é suficiente para que os novatos desenvolvam as habilidades requeridas pela atividade, em particular, aquele aprendizado que permite acelerar modos operatórios sem cometer erros e sem aumentar as chances de acidente. A fala do operador revela sua consciência em relação a esse fato, mas precisa ser acompanhada da explicitação da incompreensão da gerência sobre a formação requerida para essa atividade. As práticas denunciadas sugerem que o trabalho em questão é visto como manual e sem dificuldades.

Esse aspecto pode estar associado à maior acidentalidade dos novatos. As habilidades em questão são adquiridas com a experiência e incluem: precisão para cortar, movimentos rápidos com mãos, braços e dedos. Ou seja, é necessário que o trabalhador tenha um acompanhamento e adequação da tarefa enquanto ele desenvolve a competência tácita para o trabalho. Durante a fase de desenvolvimento dessas habilidades, a velocidade da nória no posto do iniciante deveria ser menor. $\mathrm{O}$ mesmo vale para aqueles que são antigos de empresa, mas que estão fazendo o serviço pela primeira vez, substituindo colega. As falas a seguir mostram que os operadores têm consciência das necessidades de treinamento:

- O lugar menos ruim é aonde nós estamos acostumados a trabalhar... Muita gente não gosta de substituir o colega, o serviço fica mais difícil não tendo prática.

- Quando faz pela primeira vez é ruim, cansa mais.

O cansaço explicitado pelos trabalhadores mostrou-se relevante para a análise das causas dos AT. Quando a equipe buscou compreender a fadiga relatada, encontrou dados reveladores junto ao SESMT (Serviço Especializado em Segurança e Medicina do Trabalho) da empresa: a maior causa definida de afastamento segundo CID-10 é a do grupo M que trata das doenças do sistema músculo-esquelético e do tecido conjuntivo, responsável por $27,2 \%$ dos afastamentos. Em entrevistas, esses sintomas se confirmaram:

- A gente falta por causa de dor, dói as costas, braço, ombro, cabeça.

As faltas e os afastamentos geram o rodízio de tarefas como dito anteriormente, sem planejamento, e frequentemente alguns trabalhadores são colocados em postos para os quais não possuem as habilidades necessárias. Algumas verbalizações durante as entrevistas nos apontaram esse fato:

- Quando a gente vai cobrir um colega nós não temos segurança.

Outro fator importante na causa do cansaço é a necessidade de os trabalhadores realizarem outras tarefas depois do abate. Ao término dessa tarefa, antes do término da jornada de trabalho, 
os operadores são designados para auxiliar colegas em outros setores da empresa, tais como: sala de mocotó, limpeza geral, câmara fria, sala de vergalhão, desossa de cabeça, sala de esôfago etc. Não lhes é dado o direito de recusar auxiliar nesses setores, pois, se houver recusa, recebem penalizações popularmente conhecidas como "ganchos", como explicado a seguir.

\section{Gestão autoritária}

A gestão na empresa é de tipo familiar e autoritária, praticada diretamente pelos proprietários que participam de atividades de supervisão e gestão de produção.

O autoritarismo é comprovado por práticas de suspensões do trabalho e punições com deduções dos salários mensais, denominadas "ganchos" que ocorrem em várias situações:

- Nos casos de atraso dos trabalhadores, o portão é fechado e o trabalhador é impedido de entrar, implicando na perda do salário do dia e da cesta básica;

- Como mecanismo de controle de qualidade e produtividade: Se você não fizer do jeito certo vai tomar gancho;

- Na falta de membro da equipe, outro trabalhador é designado para cobrir o posto do faltante, sem direito à recusa, sob pena de aplicação da punição ("gancho");

- Os EPIs (equipamentos de proteção individual), mesmo obrigatórios, só podem ser substituídos depois de decorridos três meses de uso. Em casos de danos ou desgaste antes desse prazo, são fornecidos mediante o desconto no salário do funcionário. Essa prática se estende à reposição de ferramentas manuais como facas e amoladores: A gente vai pegar outra [luva], eles falam que ainda está boa, mas está espetando, [...] se insistir pra trocar eles trocam, mas desconta do salário...

- Os operadores da matança só podem ir para casa após o término do processamento de toda carne abatida no dia, o que implica em prática compulsória de horas extras, sob pena de "gancho”, principalmente nos períodos de maior demanda.

O trabalhador punido com o gancho fica impedido de voltar ao trabalho, muitas vezes, por mais de um dia. Os colegas deslocados para substituí-los, não tendo as mesmas habilidades, apresentam mais chances de erros não recuperados e de acidentes. O gancho também gera insatisfação nos trabalhadores por implicar em perda de salário dos dias afastados e da cesta básica.

\section{Carência e inadequação de meios materiais}

A inadequação de equipamentos de abate e movimentação de animais e de proteção individual enseja variabilidades a serem recuperadas pelos operadores. Os prejuízos associados a esses problemas não costumam ser avaliados ou considerados no sistema.

Com o uso e o desgaste do corte, as facas perdem o fio, tornam-se "rombudas" e exigem mais força na operação. Desse modo, podem derrapar no corpo do animal e aumentar as chances de acidentes especialmente com operadores inexperientes.

Nos grupos e na interação com operadores, foi revelado que algo semelhante ocorre com as luvas de proteção. Com o tempo de uso, há desgaste e a abertura dos elos de aço, provocando o aparecimento de pontas que ferem as mãos dos trabalhadores e espetam a carne dos animais.

- Quando a luva fica velha ela cria umas farpas que grudam na mão da gente e fica espetando o dia inteiro... daí não dá pra usar.

As luvas dificultam a apreensão da faca e a pega de partes dos animais, conflitando com exigências da tarefa e contribuindo para a baixa adesão dos trabalhadores ao seu uso. O almoxarifado de EPIs localizado a 200 metros do setor de matança torna mais difícil sua substituição. A situação se agrava por se tratar de atividade que impõe desmanche em fluxo contínuo com restrições às saídas antes dos intervalos.

Outra variabilidade possível é que a pistola pneumática não mata o boi de imediato, deixando-o apenas atordoado e exigindo que o trabalhador termine a tarefa à faca, adentrando na área de circulação dos animais para esfaqueá-lo ou amarrá-lo novamente às correntes de sustentação da nória. A situação pode ser caracterizada de risco iminente devido aos golpes e coices dos animais:

- Às vezes o boi ainda está vivo e, quando isso acontece, temos que parar para matar novamente.

Esse é também o caso das carretilhas que prendem as correntes que amarram as patas do boi à nória. Por falta de manutenção preventiva, elas se desgastam e podem favorecer a queda do animal sobre o trabalhador.

- Se o boi estiver muito vivo pode escapar, é difícil [...] se amarrar errado também pode escapar.

No abate de suínos, é necessário que se amarre $\mathrm{o}$ animal ainda vivo em correntes ligadas à nória e matá-lo com punhal. O processo arcaico exige muita força nos membros superiores e favorece 
a ocorrência de AT e patologias do sistema músculo-esquelético.

A nocividade do trabalho apresenta como um dos efeitos a elevada rotatividade da força de trabalho. Com base nos dados fornecidos pela empresa, o IR (Índice de Rotatividade), foi calculado em $84 \%$ no ano de 2008 . O IR de base anual é calculado como segue: $\{[$ (admissões + demis- sões)/2]/efetivo médio ano\}x100. Para o ano de 2008, o IR na empresa foi assim calculado: $\{[(332$ $+309) / 2] / 381,3\} \times 100=84 \%$.

\section{Análise de um acidente comum no setor}

O Quadro 2 mostra síntese de acidente analisado com o MAPA.

Quadro 2. Aspectos identificados em análise de acidente no manuseio de faca ao "barbear" partes dianteiras e pescoço de suíno.

\begin{tabular}{|c|c|}
\hline MAPA & Descrição \\
\hline Resumo do AT & $\begin{array}{l}\text { Ao segurar a pata do porco com a mão direita e, com a esquerda passar a faca barbeando o animal, } \\
\text { perde o controle do movimento e é atingido no dedo indicador da mão direita, cortando-o. }\end{array}$ \\
\hline $\begin{array}{c}\text { Descrição do } \\
\text { trabalho habitual }\end{array}$ & $\begin{array}{l}\text { Trabalha em pé e utiliza faca, que é amolada constantemente. A nória corre a } 10 \mathrm{~m} / \mathrm{min} \text {. O operador } \\
\text { tem cerca de } 6 \text { segundos para barbear o animal. Inicia, raspando a face esquerda do porco. Para } \\
\text { raspar a pata, segura-a e estica-a com a mão esquerda para eliminar dobras no couro ao mesmo } \\
\text { tempo em que faz os movimentos de raspar com a mão direita. Para terminar, faz corte fundo na } \\
\text { garganta começando a partir de furo já existente (primeira punhalada) até o queixo do animal. } \\
\text { Nessa série faz cerca de } 17 \text { movimentos curtos de raspar os pelos. A velocidade da nória impõe ritmo } \\
\text { constante e intenso de trabalho, deixando pouca margem de regulação e impossibilitando pausas } \\
\text { para recuperação. }\end{array}$ \\
\hline $\begin{array}{l}\text { Análise de } \\
\text { mudanças }\end{array}$ & $\begin{array}{l}\text { Operador não habitual. Trabalhava naquele posto pela primeira vez, substituindo colega demitido e } \\
\text { sem ter recebido formação para tal. Essa forma de gestão de pessoal é habitual. A designação de } \\
\text { novatos não é acompanhada de mudanças na velocidade da nória. } \\
\text { Não foram identificadas mudanças no modo operatório que explicassem a perda de controle na } \\
\text { raspagem de pelos do porco levando ao corte sofrido pelo operador. É possível que a falta de } \\
\text { habilidade do operador novato, o cansaço e a perda do corte da faca tenham contribuído para o } \\
\text { descontrole durante tentativa de aceleração do Modo Operatório para atender às pressões de tempo } \\
\text { impostas pela velocidade da nória. O modo operatório habitual é perigoso e mudanças mínimas } \\
\text { podem ensejar descontrole do gesto. O cansaço pode decorrer do fato de o abate dos porcos ocorrer } \\
\text { à tarde, depois de manhã de trabalho duro no abate de bois. } \\
\text { O uso constante da faca desgasta o seu fio e aumenta as dificuldades da tarefa. }\end{array}$ \\
\hline $\begin{array}{l}\text { Análise de } \\
\text { Barreiras }\end{array}$ & $\begin{array}{l}\text { A única barreira disponibilizada pela empresa é par de luvas de malha de aço que dificulta os } \\
\text { movimentos de pega da peça, da faca e a raspagem do couro do animal. Por isso, o não uso da } \\
\text { barreira é habitual e conhecido de gestores da produção e da segurança. Com o desgaste, a malha de } \\
\text { aço da luva abre-se, espeta as mãos do operador e gruda na carne do animal. A velocidade constante } \\
\text { da nória e a distância do almoxarifado inviabilizam a troca de EPIs danificados. }\end{array}$ \\
\hline $\begin{array}{l}\text { Ampliação } \\
\text { conceitual }\end{array}$ & $\begin{array}{l}\text { Situação vulnerável na qual pequenas mudanças na situação de trabalho podem ocasionar o AT. A } \\
\text { não utilização das luvas pelas circunstâncias descritas pode configurar by pass previsível às barreiras } \\
\text { de proteção disponibilizadas pela empresa. }\end{array}$ \\
\hline $\begin{array}{l}\text { Gestão de } \\
\text { segurança }\end{array}$ & $\begin{array}{l}\text { Gestão de segurança que desconsidera habilidades requeridas na atividade e insiste em recomendar } \\
\text { medidas de segurança formal (fornecimento de EPI) reveladas inadequadas pela repetição de } \\
\text { acidentes assemelhados. } \\
\text { Falha na interpretação do significado da repetição de acidentes assemelhados e fracasso das } \\
\text { recomendações de prevenção ensejando perda de janela de oportunidade para o aprendizado } \\
\text { organizacional e alimentação de práticas de atribuição de culpa às vítimas de acidentes. } \\
\text { Falha na gestão de EPI associada a prazos superiores aos tempos de desgaste e cobrança do mesmo } \\
\text { para a reposição dos equipamentos. }\end{array}$ \\
\hline $\begin{array}{l}\text { Gestão de } \\
\text { produção }\end{array}$ & $\begin{array}{l}\text { Falha na gestão de pessoal associada a remanejamento de operadores despreparados, autoritarismo, } \\
\text { elevados absenteísmo e rotatividade de mão de obra. } \\
\text { Falhas na gestão de produção associada à manutenção de metas de produção/velocidade da nória na } \\
\text { linha operada por novatos e à fixação de metas além da capacidade instalada do sistema. }\end{array}$ \\
\hline
\end{tabular}


$\mathrm{O}$ acidente ocorreu com trabalhador que estava em seu primeiro dia na raspagem de pelos dos suínos, após ser remanejado para substituir colega demitido. $\mathrm{O}$ acidente consistiu em um gesto que foi além do previsto e atingiu o outro braço do operador.

No frigorífico, a velocidade da nória determina que o operador realize seus movimentos de forma rápida e acelerada, em cerca de seis segundos. Na prática, a aquisição da capacidade de acelerar o modo operatório está associada ao desenvolvimento de "automatismos", sem necessitar mobilizar a atenção, aprender atalhos ou a eliminação de gestos inúteis, etc. A aquisição dessa habilidade vem com a experiência.

Uma das consequências disso é que apenas conhecer a sequência de movimentos a serem realizados não significa saber fazer o trabalho. Em outras palavras, o trabalho não é tão simples como pode parecer ao observador externo ou ao gestor de pessoal. Por sua vez, o uso das luvas se revela dificultador do desenvolvimento e da adoção do modo operatório nas condições exigidas no frigorífico.

A análise de barreiras revela tratar-se de acidente durante operação habitual que exige modo operatório perigoso adotado em condições de aceleração.

A análise de mudanças revela dois aspectos principais que se mostram interligados: o fracasso de gesto habitual e a realização de tarefa por operador não habitual. $\mathrm{O}$ fato de o novato precisar realizar a tarefa no mesmo tempo em que os colegas experientes a fazem aumentam as chances de mudanças em modo operatório capazes de levar ao acidente.

A prevenção aqui precisa explorar aspectos da gestão de pessoal, em especial os remanejamentos improvisados e as práticas associadas ao aumento do absenteísmo e da rotatividade. A mera definição de critérios de remanejamentos é insuficiente para lidar com a acidentalidade nesse sistema. Uma das estratégias úteis nesse sentido parece ser a de incentivar discussões sobre a atividade dos depiladores, mostrando ser enganosa a idéia de que seja trabalho manual simples capaz de ser realizado por qualquer um a qualquer momento e sem aprendizagem específica. A aquisição de habilidades de aceleração de modos operatórios na tarefa é importante. Há necessidade de estudos que permitam definir as melhores condições de equilíbrio entre ritmo e competências dos trabalhadores ou até a adoção de novas formas de organização do trabalho que eliminem a imposição de metas inatingíveis e de controles rígidos como os mantidos até então.

Nesse acidente, a contribuição da ampliação conceitual da análise veio, sobretudo, com a incorporação de achados provenientes da AET realizada como ponto de partida da intervenção na empresa. Por isso a exploração da contribuição desses aspectos nas origens de acidentes ficou facilitada e deve ser aproveitada na busca da construção de condições sociais para a prevenção.

\section{O Diagnóstico e as recomendações}

Constatou-se que o processo de gênese dos acidentes é provocado por rede de fatores em interação e não por atos inseguros ou condições inseguras, conforme conclusões habituais do SESMT da empresa.

A elevada acidentalidade está associada por um lado ao trabalho intenso, determinado pelo baixo efetivo associado à rapidez da nória e à precariedade de meios técnicos e materiais, como o sistema arcaico de abate, a inadequação das luvas às exigências da tarefa e a precarização no sistema de fixação e elevação dos animais. Por outro lado, o trabalho intenso gera fadiga, que leva ao absenteísmo e à rotatividade sem planejamentos. Diante das faltas ou demissões, a empresa convoca inexperientes que se acidentam. Esse círculo vicioso é agravado por relações de trabalho autoritárias, que diminuem as margens de regulação dos operadores.

A partir do diagnóstico, elaboraram-se recomendações que foram apresentadas em Mesa Redonda, da qual participaram o Cerest, a direção da empresa, o sindicato dos trabalhadores e Auditor do MTE.

Algumas recomendações foram aceitas e outras rejeitadas pela direção da empresa, conforme se verifica nas duas colunas do lado direito do Quadro 1.

O diagnóstico permitiu a ampliação do leque de exigências, quando comparado com o de 1997. A nova abordagem incide sobre dimensões não observadas anteriormente, como os aspectos do gerenciamento da produção com a necessidade de equacionar o efetivo com a carga de trabalho e a questão do autoritarismo, antes invisíveis para a equipe. A nova exigência alcança pontos centrais relativos ao abate e exige alterações de modo a diminuir a força física e a exposição à situação de elevado risco, tanto no aprisionamento como no abate manual de animais. A resposta da empresa parece demonstrar maior adesão a alguns aspectos técnicos materiais, em detrimento de alterar as práticas autoritárias como os "ganchos". 


\section{Discussão}

O Quadro 3 possibilita comparação entre as duas abordagens mostrando que a nova proposta de intervenção tem alcance maior do que anterior.
O estudo permitiu comparar duas abordagens de vigilância em acidentes de trabalho numa mesma empresa. Na primeira, a intervenção incide basicamente em itens constantes das Normas Regulamentadoras, não alcançando aspec-

Quadro 3. Síntese comparativa das duas abordagens.

\begin{tabular}{|c|c|c|}
\hline $\begin{array}{l}\text { Aspectos da } \\
\text { intervenção }\end{array}$ & Vigilância de 1997 & Pesquisa / intervenção de 2008 \\
\hline Demanda & $\begin{array}{l}\text { Elevada acidentalidade conforme dados das } \\
\text { CATs }\end{array}$ & $\begin{array}{l}\text { Elevada acidentalidade conforme dados das } \\
\text { CATs. }\end{array}$ \\
\hline Ação institucional & Ampla (MTE, sindicato, MPT, PST) & Ampliada para os Centros de Pesquisa \\
\hline Métodos & $\begin{array}{l}\text { Observação - inspeção, checagem de itens da } \\
\text { legislação, registro fotográfico }\end{array}$ & $\begin{array}{l}\text { Análise da demanda, negociação com a direção } \\
\text { da empresa, registro de verbalizações, grupo de } \\
\text { análise coletiva do trabalho (ACT), observação, } \\
\text { análise de ATs ocorridos (MAPA), registro } \\
\text { fotográfico, filmagem, diagnóstico e validação. }\end{array}$ \\
\hline Alcance & $\begin{array}{l}\text { Circunscrita e pontual, incide sobre os aspectos } \\
\text { materiais e visíveis especialmente os Itens das } \\
\text { Normas Regulamentadoras do MTE. } \\
\text { Não investiga acidentes ocorridos e sua história. }\end{array}$ & $\begin{array}{l}\text { Ampliado para condições e causas latentes dos } \\
\text { acidentes (ritmo, dimensionamento do efetivo, } \\
\text { autoritarismo na gestão de pessoal, gestão de } \\
\text { produção); incide sobre a concepção do } \\
\text { processo técnico e propõe novos métodos e } \\
\text { técnicas para abate de animais. }\end{array}$ \\
\hline $\begin{array}{l}\text { Impacto da } \\
\text { intervenção }\end{array}$ & $\begin{array}{l}\text { Mesmo atendendo parcialmente as exigências, a } \\
\text { acidentalidade continua elevada uma vez que } \\
\text { não são alterados seus determinantes. } \\
\text { Intervenção não altera a essência da } \\
\text { precarização e insalubridade das relações de } \\
\text { trabalho. Precarização se mantém. }\end{array}$ & $\begin{array}{l}\text { Empresa é desafiada a alterar a forma de gestão } \\
\text { da produção e as relações autoritárias de } \\
\text { trabalho. Empresa aceita com mais facilidade as } \\
\text { mudanças técnicas e resiste a alterar o estilo } \\
\text { autoritário de gestão. Necessidade de aprimorar } \\
\text { as estratégias para obter sucesso na } \\
\text { intervenção. }\end{array}$ \\
\hline $\begin{array}{l}\text { Natureza da } \\
\text { Intervenção }\end{array}$ & $\begin{array}{l}\text { Vigilância tipo Tutela Estatal de comando } \\
\text { controle - propício a ações reativas e defensivas } \\
\text { por parte da empresa. }\end{array}$ & $\begin{array}{l}\text { Vigilância tipo negocial e participativa, sem } \\
\text { abrir mão do papel do Estado. Cria ambiente } \\
\text { mais propício à cooperação, ao acesso às } \\
\text { informações, facilitando adesão e prevenção/ } \\
\text { transformação. }\end{array}$ \\
\hline Saber & $\begin{array}{l}\text { Do especialista Sindicato pouco influi com } \\
\text { informações, pois não as possui no chão de } \\
\text { fábrica. }\end{array}$ & $\begin{array}{l}\text { Informações e saber dos trabalhadores são } \\
\text { fundamentais para o diagnóstico. O saber é } \\
\text { compartilhado. Saber técnico multiprofissional } \\
\text { + saber empírico. }\end{array}$ \\
\hline Olhar & $\begin{array}{l}\text { Externo ao trabalho. É o olhar informado pelas } \\
\text { disciplinas clássicas. Fator de risco visto em si, } \\
\text { isolado do processo de trabalho. }\end{array}$ & $\begin{array}{l}\text { Olhar por "dentro do trabalho" ocupa-se da } \\
\text { atividade de trabalho. Risco é visto como uma } \\
\text { relação do sujeito com a situação de trabalho e } \\
\text { não como fator ambiental. }\end{array}$ \\
\hline $\begin{array}{l}\text { Impactos junto } \\
\text { aos serviços }\end{array}$ & $\begin{array}{l}\text { Conhecimento e experiência no } \\
\text { enquadramento legal e normativo. Habilidades } \\
\text { para monitoramento de indicadores } \\
\text { epidemiológicos. }\end{array}$ & $\begin{array}{l}\text { Novo olhar sobre os determinantes dos riscos } \\
\text { do trabalho. Novos conhecimentos sobre a } \\
\text { causalidade e sobre os métodos de investigação } \\
\text { dos acidentes. Aquisição de habilidades para } \\
\text { interação com operadores (método } \\
\text { qualitativo). }\end{array}$ \\
\hline
\end{tabular}


tos da dimensão organizacional e outros determinantes dos eventos.

Durante 10 anos, mesmo atendendo boa parte das exigências dos órgãos públicos, a empresa permaneceu entre as $20 \mathrm{com}$ maiores proporções de incidência de AT no município, o que pode ser explicado, dentre outros fatores, pela limitação das exigências formuladas. Esses achados parecem revelar limites e insuficiências do paradigma clássico. A crença de que a segurança seria determinada pelo cumprimento de normas e prescrições revela-se insustentável. Na vida real, a adesão às regras pode se dar de forma burocrática e sem impactos na segurança real como, aparentemente, ocorreu nessa empresa.

O estudo de 2008 possibilitou compreender o círculo vicioso dos acidentes e seus determinantes que necessitam ser alterados para se alcançar a prevenção. Os achados são compatíveis com conceitos atuais que mostram a participação decisiva dos aspectos organizacionais na gênese dos acidentes ${ }^{3,4}$.

Para as disciplinas clássicas como a Medicina do Trabalho e Higiene e Saúde Ocupacional, o risco é visto pelos especialistas de modo externo ao trabalho e isolado da atividade. Enquanto isso, na abordagem da ergonomia, ele é visto como relação que emana do real, só apreendido com a ajuda do saber-fazer dos operadores, exigindo olhar e metodologia apropriados.

As contribuições da medicina social latinoamericana auxiliam na explicação de macrodeterminações da relação trabalho-saúde, no entanto revelam-se insuficientes no nível singular das relações entre indivíduo e situações de trabalho. Sem negar a explicação macro, essa pesquisa traz elementos que mostram a centralidade da atividade de trabalho para a compreensão das mediações presentes na relação entre macrodeterminantes, o fazer e a saúde.

Segundo Wisner ${ }^{13}$ a ergonomia é a arte (técnica) na qual são utilizados o saber tecnocientífico e o saber dos trabalhadores sobre sua própria situação de trabalho. "Seu princípio é em si revolucionário, pois faz pensar que os intelectuais e cientistas têm algo a aprender a partir do comportamento e do discurso dos trabalhadores"13. Tendo em vista sua invisibilidade, o acesso à atividade requisita novo olhar, nova escuta e portanto nova modalidade de interação com os operadores. Um olhar etnográfico ${ }^{20}$ distinto do olhar externo do especialista.

A legislação vigente possibilita aos agentes públicos intervir sobre a organização do trabalho como prevê o Código Sanitário do Estado de São
Paulo $^{21}$ e a NR 17 - ergonomia ${ }^{17}$. No entanto o acesso à dimensão organizacional requer metodologia específica, viabilizada pela inclusão da academia nas articulações que possibilitou a capacitação da equipe e a execução de projetos de pesquisa.

A ação de 1997, mesmo apoiada em indicadores epidemiológicos e acompanhada pelo controle social, seguiu ainda o modelo de ação de vigilância tipo Comando - Controle Estatal que normalmente gera condutas defensivas, restritas, pontuais e limitadas ao já normatizado, o que a aproxima do modelo de fiscalização tradicional ${ }^{22}$.

Já a pesquisa intervenção de 2008, mesmo em ambiente autoritário e hostil como o da empresa estudada, criou ambiente mais propício ao diálogo e à cooperação, indispensáveis para a compreensão, a adesão e a transformação da realidade, $o$ que a aproxima da abordagem de saúde pública adotada pelo NIOSH para pesquisa/intervenção nos acidentes considerados prioritários conforme Stout ${ }^{23}$. Segundo o autor, essa abordagem compreende as seguintes etapas: identificação e priorização de problemas através de sistemas de informação e vigilância; quantificação e priorização dos fatores de risco através da pesquisa analítica; identificação de estratégias já existentes ou desenvolvimento de novas estratégias ou tecnologias para prevenir acidentes de trabalho; transferência e implementação de medidas de controle de acidentes mais efetivas; avaliação e monitoramento da intervenção. Stout ${ }^{23}$ explica ainda que o modelo utiliza abordagem organizacional e multidisciplinar, incluindo parcerias com profissionais, indústrias e agentes públicos, uma vez que a pesquisa realizada de modo isolado pode falhar em gerar impacto nos locais de trabalho e que é frequente verificar que as recomendações não são transformadas em ações de prevenção.

Sem abrir mão de medidas coercitivas, inerentes à ação estatal para preservar o interesse coletivo, o estudo indica a necessidade de ampliação das abordagens e do olhar dos agentes de vigilância para que acertem nos alvos principais, aumentando a eficiência e o alcance das intervenções.

A metodologia empregada em 2008 mesmo incorporando elementos da anterior, ao dar visibilidade a dimensões latentes como a organizacional, mostra-se mais apropriada aos objetivos preventivos, o que indica sua importância para a área da Vigilância em Saúde do Trabalhador.

O domínio da metodologia proposta pressupõe investimento na formação das equipes para o conhecimento dos conceitos e métodos da ergonomia da atividade e para a análise de acidentes usando o MAPA. 
Os indicadores epidemiológicos sobre a acidentalidade permitiram, desde o primeiro período em 1997, selecionar a empresa como um dos alvos prioritários para ações de prevenção. Só no segundo momento, quando se articulou a informação epidemiológica com o instrumental analítico (MAPA e ergonomia da atividade), conseguiu-se dar visibilidade aos determinantes organizacionais dos acidentes, aumentando o repertório da equipe para o enfrentamento da complexidade dos fenômenos tratados.

O caso reforça as diretrizes da Vigilância em Saúde do Trabalhador, uma vez que o conhecimento do trabalho real e a intervenção preventiva só são possíveis com a participação ativa do trabalhador nos locais de trabalho. Infelizmente essa participação ocorre de modo ainda limita- do pelos constrangimentos de contexto autoritário de subordinação dos trabalhadores e pela ausência de organização sindical autônoma. Apesar disso, trabalhadores desenvolveram confiança na equipe, o que permitiu acesso a informações não coletadas na abordagem tradicional e a diversas relações entre esses achados e a acidentalidade. No entanto esses atores ainda não se colocam na posição de protagonistas principais da luta pela saúde no trabalho, papel hoje ocupado principalmente por atores dos órgãos públicos como o Cerest, a representação local do MTE e o Ministério Público do Trabalho.

Novos estudos são necessários para avaliar o alcance da nova abordagem, seus impactos na alteração da situação acidentária na empresa e em outras organizações no território.

\section{Colaboradores}

RAG Viela, IM Almeida e RWB Mendes participaram da elaboração do manuscrito em todas fases.

\section{Agradecimentos}

Clarice A. Bragantini, Priscila G. S. Rodrigues e André F. Martins do Cerest Piracicaba pela participação na pesquisa de campo. Agradecimentos aos auditores do MTE, Gil Vicente F. Ricardi e Antenor J. Varolla, pelo apoio e ações interinstitucionais. Projeto apoiado pela linha de pesquisa em políticas públicas (FAPESP). 


\section{Referências}

1. Santana VS, Araújo-Filho JB, Albuquerque-Oliveira PR, Barbosa-Branco A. Acidentes de trabalho: custos previdenciários e dias de trabalho perdidos. Rev Saude Publica 2006; 40(6):1004-1012.

2. Laflamme L. A Better Understanding of Occupational Accident Genesis to improve Safety in the Workplace. Journal of Occupational Accident 1990; 12(1-3):155-165.

3. Llory, M. Acidentes Industriais o Custo do Silêncio. Rio de Janeiro: MultiMais; 1999.

4. Reason JT. Managing the risks of organizational Accidents. $6^{\text {th }}$ Ed. Burlington: Ashgate; 2002.

5. Vilela RAG, Iguti MA, Almeida IM. Culpa da Vítima um modelo para perpetuar a impunidade nos Acidentes de Trabalho. Cad Saude Publica 2004; 20(2): 570-579.

6. Almeida IM. Trajetória da análise de acidentes: o paradigma tradicional e os primórdios da ampliação da análise. Interface Comunic Saúde Educ 2006; 10(19):185-202.

7. Assunção AA, Lima FAP. A contribuição da ergonomia para a identificação, redução e eliminação da nocividade do trabalho. In: Mendes R, organizador. Patologia do Trabalho. Rio de Janeiro: Atheneu; 2003. p. 1768-1789.

8. Laurell AC, Noriega M. Processo de Produção e Saúde Trabalho e desgaste Operário. São Paulo: Hucitec; 1989.

9. Mendes R, Dias EC. Da medicina do trabalho à saúde do trabalhador. Rev Saude Publica 1991; 25(5): 341-349.

10. Brasil. Ministério da Saúde. Portaria n. ${ }^{\circ} 3.120$ de 01 de julho de 1998. Diário Oficial da União 1998; 14 jul.

11. Vilela RAG, Ricardi GVF, Iguti AM. Experiência do Programa de Saúde do Trabalhador de Piracicaba: Desafios da Vigilância em Acidentes do Trabalho. Inf Epidemiológico SUS 2001; 10(2):81-92.

12. Cordeiro R, Vilela RAG, Medeiros MAT, Gonçalves CGO, Bragantini CA, Varolla AJ, Stephan C. O sistema de vigilância de acidentes do trabalho de Piracicaba, São Paulo (SP). Cad Saude Publica 2005; 21(5):1574-1583.

13. Wisner A. Por dentro do trabalho ergonomia: métodos e técnicas. São Paulo (SP): Oboré/FTD; 1987.

14. Guérin F, Laville A, Daniellou F, Duraffourg J, Kerguelen A. Compreender o trabalho para transformálo. A prática da Ergonomia. 2a Edição. São Paulo: Edgard Blücher; 2004.
15. Almeida IM, Vilela RAG. Modelo de Análise e Prevenção de Acidentes de Trabalho - MAPA. Piracicaba: Cerest Piracicaba; 2010.

16. Vasconcellos MC, Pignatti MG, Pignati WA. Emprego e acidentes de trabalho na indústria frigorífica em áreas de expansão do agronegócio, Mato Grosso, Brasil. Saúde e Sociedade 2009; 18(4):662-672.

17. Brasil. Ministério do Trabalho. Portaria MTB No 3.214, de 8 de junho de 1978. Aprova as Normas Regulamentadoras - NR - do Capítulo V, Título II, da Consolidação das Leis do Trabalho, relativas a Segurança e Medicina do Trabalho. Diário Oficial da União 1978; 6 jul.

18. Brasil. Lei Federal no 6.437 , de 20 de agosto de 1977. Configura infrações à legislação sanitária federal, estabelece as sanções respectivas, e dá outras providências. Diário Oficial da União 1977; 24 ago.

19. Oliveira RC. O trabalho do antropólogo: olhar, ouvir, escrever. In: O trabalho do antropólogo. $2^{\mathrm{a}}$ Edição. SP: UNESP; 2000. p. 17-36.

20. Ferreira LL. Analise Coletiva do trabalho. Rev Bras Saúde Ocup 1993; (21):7-19.

21. São Paulo. Decreto No 12.342 , de 27 de setembro de 1978. Aprova o Regulamento a que se refere o artigo 22 do Decreto-Lei n. ${ }^{\circ} 211$, de 30 de março de 1970, que dispõe sobre normas de promoção, preservação e recuperação da saúde no campo de competência da Secretaria de Estado da Saúde. Secretaria do Governo 1978; 27 set.

22. Vasconcelos LCF, Ribeiro, FSN. Investigação epidemiológica e intervenção sanitária em saúde do trabalhador: o planejamento segundo bases operacionais. Cad Saude Publica 1995; 13(2):269-275.

23. Stout NA. The public health approach to occupational injury research: From surveillance to prevention. Safety Science 2008; 46(2):230-233.

Artigo apresentado em 20/07/2011

Aprovado em 27/07/2011

Versão final aprovada em 20/09/2011 